\title{
The effect of the type of feeding on weight gain and illnesses in infants
}

\author{
By A. E. DUGDALE \\ Department of Paediatrics, University of Malaya, \\ Kuala Lumpur, Malaysia \\ (Received 20 October $1970-$ Revised 25 May r97I)
}

\begin{abstract}
I. The effects of breast-feeding and artificial feeding have been analysed for a group of 250 infants from lower socio-economic, urban families in Kuala Lumpur, Malaysia.

2. The factors considered were the ethnic group, the sex of the infant, the size and income of the family and the type of milk fed. No infant in the study was given 'non-milk' feeds before the age of 40 weeks.

3. The effects of these factors on the weight gains and the number of reported illnesses up to the age of 40 weeks have been analysed.

4. At no time in the first 40 weeks did breast-fed infants gain weight significantly more rapidly than artificially fed infants. After the age of 20 weeks, artificially fed infants gained significantly more weight than breast-fed infants.

5. The type of feeding had no statistically significant effect on the frequency of minor respiratory or alimentary illnesses.

6. In this community, the welfare of the family often depends on the earnings of the mother, who has to make the choice between breast-feeding and paid employment. In the group studied, breast-feeding appears to offer no advantages over artificial feeding. The principle guiding the Maternal and Child Health staff when advising the mother should be the welfare of the whole family.
\end{abstract}

For many years, paediatricians and nutrition scientists have stressed the dangers of artificial feeding of infants. The differing compositions of human and cow's milk is reflected in biochemical differences between breast-fed and bottle-fed infants (Oppé \& Redstone, 1968), but the long-term effects of these differences have not been established. In rural areas of developing countries, contamination and overdilution of artificial feeds may lead to increases in disease and death of infants (Scrimshaw, Taylor \& Gordon, 1968), but in most parts of the world, the health of infants is improving in spite of a reduction in breast-feeding. It would therefore be difficult to demonstrate that artificial feeding is wholly bad.

In low-class, urban dwellers in developing countries, the situation is intermediate between the ignorance of the undeveloped rural areas and the sophistication of Western society. Economic deprivation is a major problem with this group. If artificial feeding can reasonably be substituted for breast-feeding, mothers can be released from home for gainful employment. In this paper, I have examined the effects on the infant of various social and nutritional factors in an attempt to assess their importance.

\section{MATERIAL AND METHODS}

The information used in this study was obtained retrospectively from the records of the $\mathrm{MCH}$ clinics in Kuala Lumpur, Malaysia. When an infant was first brought 
to the clinic, the basic family information was recorded. At each visit, the type of feeds, any illness reported by the mother or noted by the nurse and also any treatment or immunizations were recorded by the nurse, together with the weight of the infant. The record cards for each year had been put in serial order and stacked on shelves in bundles of 100 . Bundles of cards were taken for the years 1960,1963 and 1965 until a sufficient number had been obtained. Although this method of sampling is not strictly random, bias seems unlikely. The data were coded, transferred to 80-column punched cards and analysed by computer. For this study, infants were selected from the main sample of 2000 if they met the following criteria: ( $\mathrm{I}$ ) the first visit to the clinic was before 6 weeks of age, the last visit was after the age of 40 weeks, and the total number of visits was at least twelve; (2) the birth weight was $2.5 \mathrm{~kg}$ or more; (3) there was no record of 'non-milk' supplementary feeds before the age of 40 weeks, and (4) the information was complete. These conditions were met by I I9 Malay infants and $\mathrm{r}_{3} \mathrm{I}$ Chinese infants.

The criteria used in the analysis were as follows: (1) Ethnic group. (2) Size of the family: those families with one or two living children were classed as 'small', the remainder were classed as 'large'. (3) Family income: families whose total income was less than $\$ M_{1} 20$ per month were classed as 'low income', the remainder were classed as 'high income'. An unskilled labourer in Kuala Lumpur at that time earned about $\$ M 80-100$ per month $\left(\$ M_{I}=12\right.$ p). (4) Duration of breast-feeding: combined feeding with breast and bottle was uncommon; when it did occur, it was included in the breast-feeding. (5) Weight of the infant at each visit to the clinic. (6) The illnesses reported at each visit: the illnesses were classified as respiratory, alimentary and other. The respiratory illnesses were mostly mild upper respiratory infections, the alimentary illnesses were usually minor disturbances of bowel function, commonly mild diarrhoea. In the clinics, it was seldom possible to decide whether the alimentary disturbances were due to infection, dietary disturbance or some other cause.

The weight curves of the infants were smoothed by using the least-squares criterion to fit logistic equations. Weights at $10,20,30$ and 40 weeks were taken from the computed curve. The frequency of each type of illness was calculated as the number of episodes per year of observation. Multifactorial analysis of variance was used to analyse the significance and to determine the magnitude of effect of the various factors.

\section{RESULTS}

The population attending the $\mathrm{MCH}$ clinics was wholly urban and mainly labouring and lower middle class. Analysis of the weight gains of the 2000 infants showed that they grew rapidly during the first few months but later in the ist year their growth was slow (Fig. 1).

The distribution of family size, income, ethnic group and sex of the infants for the 250 infants in this study are shown in Table r. Of the $25^{\circ}$ infants, $30 \%$ received no breast milk and $76 \%$ had been weaned by the age of 40 weeks. 


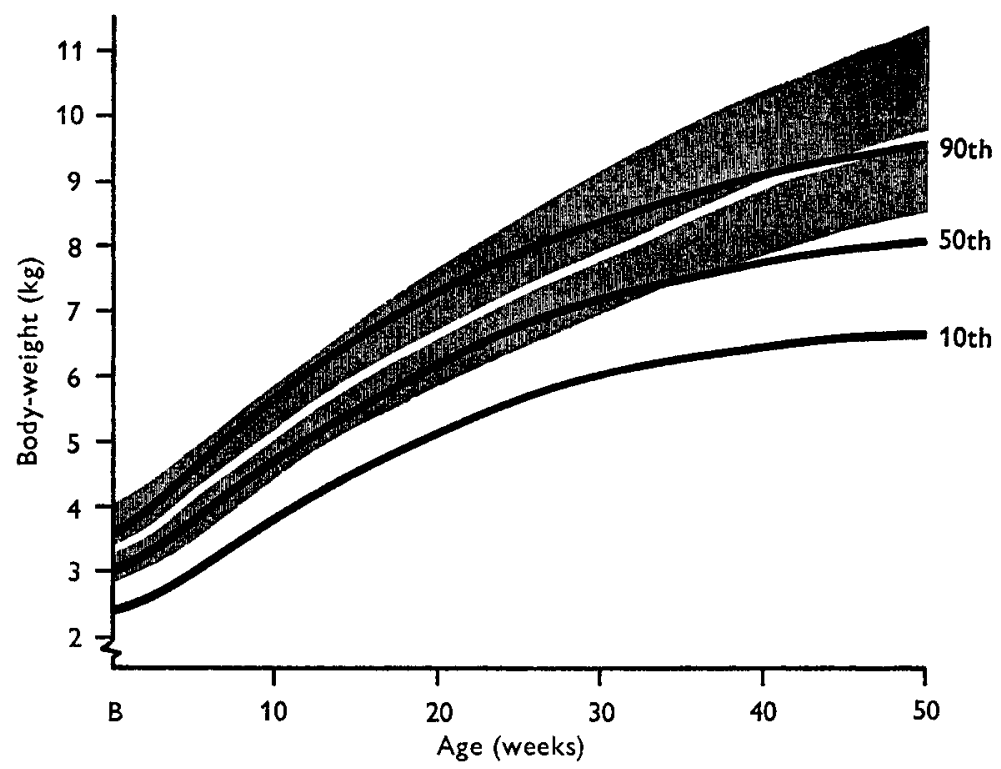

Fig. I. Weight gains of infants who attended the MCH clinics in Kuala Lumpur, Malaysia, during their Ist year of life. The shaded area shows the Stuart-Stevenson Boston Standards.

Table I. Distribution of infants in the sample by race, family size, family income and duration of breast-feeding

\begin{tabular}{|c|c|c|c|c|c|c|c|c|c|}
\hline \multirow[b]{2}{*}{ Race } & \multirow[b]{2}{*}{$\begin{array}{c}\text { Family } \\
\text { size }\end{array}$} & \multirow[b]{2}{*}{ Income } & \multirow[b]{2}{*}{$\begin{array}{c}\text { At } \\
\text { birth }\end{array}$} & \multicolumn{5}{|c|}{ Age at weaning (weeks) } & \multirow[b]{2}{*}{ Total } \\
\hline & & & & $<\longdiv { 1 0 }$ & $10-19$ & $20-29$ & $3^{\circ}-39$ & $\geqslant 40$ & \\
\hline \multirow[t]{4}{*}{ Malay } & Small & Low & 4 & 5 & 3 & 2 & 3 & 7 & 24 \\
\hline & & High & 8 & 2 & 6 & 3 & 0 & 3 & 22 \\
\hline & Large & Low & 7 & 5 & 6 & 3 & 3 & 13 & 37 \\
\hline & & High & 5 & ro & 7 & 2 & I & I I & $3^{6}$ \\
\hline \multirow[t]{4}{*}{ Chinese } & Small & Low & 2 & 5 & 5 & 3 & 2 & 4 & $2 \mathrm{I}$ \\
\hline & & High & $2 I$ & 8 & 3 & 2 & 0 & 7 & $4 \mathrm{I}$ \\
\hline & Large & Low & 8 & 2 & 4 & 2 & 0 & 8 & 24 \\
\hline & & High & 19 & 8 & 5 & 5 & $I$ & 7 & 45 \\
\hline Total & & & 74 & 45 & 39 & 22 & IO & 60 & 250 \\
\hline
\end{tabular}

Analysis of factors affecting the weight gains of infants

The weight gains of infants were determined from the computed curve for the age groups: birth, Io weeks, IO-20 weeks, 20-30 weeks and 30-40 weeks. Multifactorial analysis of variance was performed on the weight gains during these intervals to determine which factors had a significant effect. If the type of feeding of the infant changed during the 10-week period, the infant was excluded from that particular analysis. The results are shown in Table 2. Each line in this table gives the results of a five-factor analysis of variance.

From Table 2, it can be seen that the ethnic group of the infant had a statistically significant effect on the weight gain only in the first ro weeks, when Chinese infants gained weight more rapidly than Malay infants. The sex of the infant affected the 


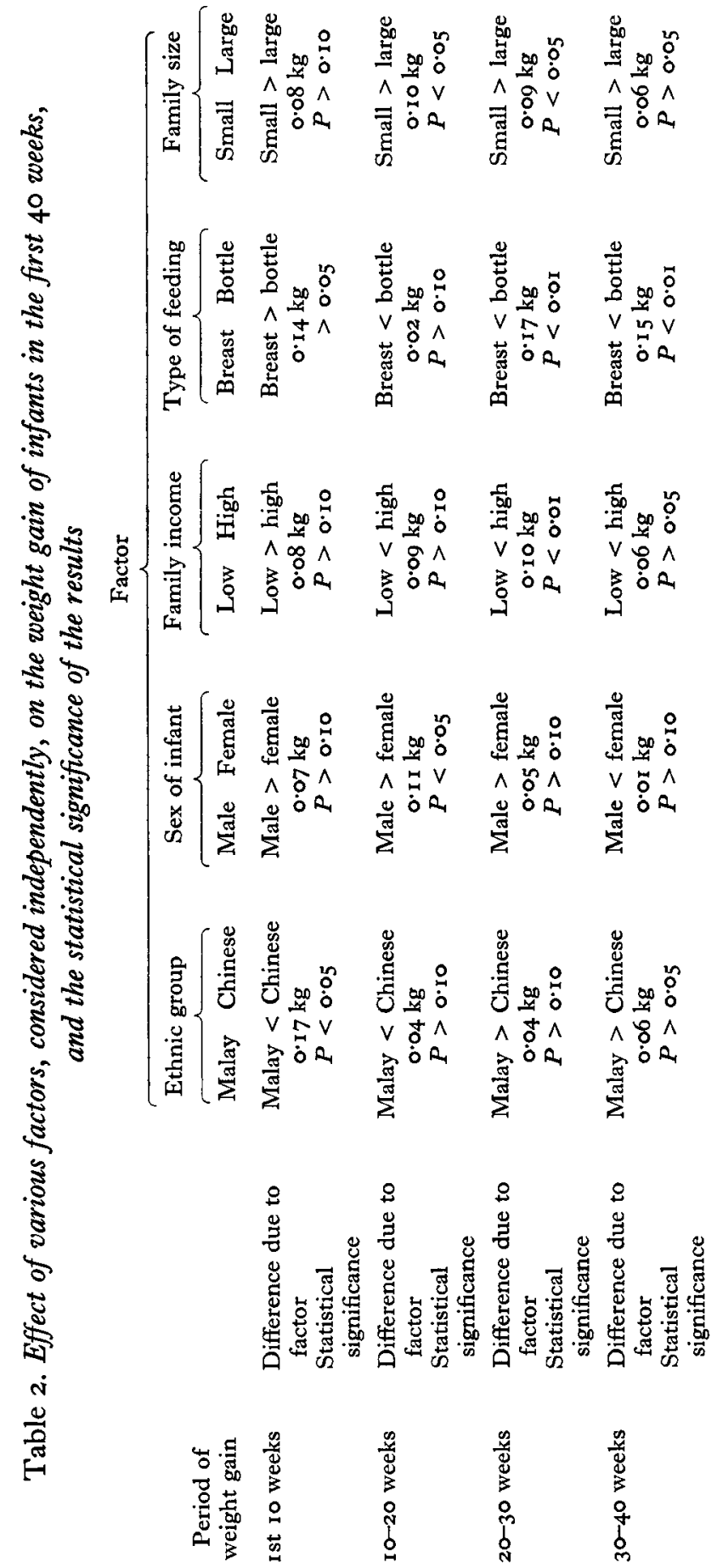


weight gain significantly only in the second ro-week period. Infants in large families tended to grow more slowly than infants in small families. During the ro to 20-week period the difference due to family size was $0.10 \mathrm{~kg}$, which was about $6 \%$ of the average weight gain during this period; during the 20 to 30 -week period the difference was $0.09 \mathrm{~kg}$, or about $8 \%$ of the average weight gain. Both these differences were statistically significant $(P<0.05)$.

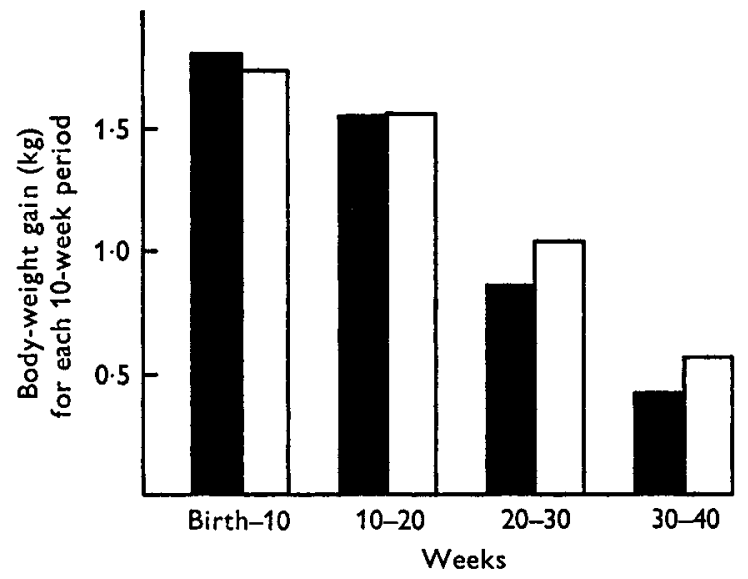

Fig. 2. Weight gains of Malay infants during the first 40 weeks of life, showing the differences due to the type of feeding given. Other children showed a similar pattern. $\square$, breast-fed; $\square$, bottle-fed.

The effect of the type of feeding is shown in Fig. 2. From birth to ro weeks of age, breast-fed infants gained more weight than did bottle-fed infants (difference $=0.14 \mathrm{~kg}$, about $7 \%$ of weight gain) but the difference was not significant at the 0.05 level of probability. From 10-20 weeks, the type of feeding made almost no difference to the weight gain (difference $=0.0 \mathrm{Ig}$, about $\mathrm{I} \%$ of the average weight gain). During the period from 20 to 30 weeks, artificially fed infants gained considerably more weight (difference $=0.17 \mathrm{~kg}$, about $\mathrm{I} 7 \%$ of the average weight gain; statistical significance $P<0.01$ ) and in the period $30-40$ weeks, artificially fed infants again gained more weight than breast-fed infants (difference $=0.15 \mathrm{~kg}$, about $2.9 \%$ of the average weight gain; statistical significance $P<0.01$ ).

To confirm the results of these cross-sectional analyses, individual records were examined to determine the effect on the rate of weight gain of the change from breastfeeding to artificial feeding. The pattern varied, but in some infants there was unequivocal evidence for an increase in the rate of weight gain following the change from breast-feeding to bottle-feeding (Fig. 3).

\section{Effect of the factors on the frequency of respiratory and alimentary illnesses}

Multifactorial analyses of variance were done to test the effects of factors on the illness rate. Respiratory illnesses were reported significantly more frequently among Malay infants (difference $\mathrm{I} \cdot 09$ episodes per year, about $12 \%$ of the average total), and in low-income families (difference 148 episodes per year, about $16 \%$ of the average 
number). The sex of the child and the number of children in the family had no significant effect on the number of respiratory illnesses. The type of feeding had no significant effect (Fig. 4).

The frequency of alimentary illnesses was significantly affected by the size of the families (large families had more illnesses (difference 0.40 episodes per year, about $30 \%$ of the average number; $P<0.05$ ), but none of the other factors had any significant effect. The relationship between the number of episodes and the duration of breast-feeding is shown in Table 3 and in Fig. 4.

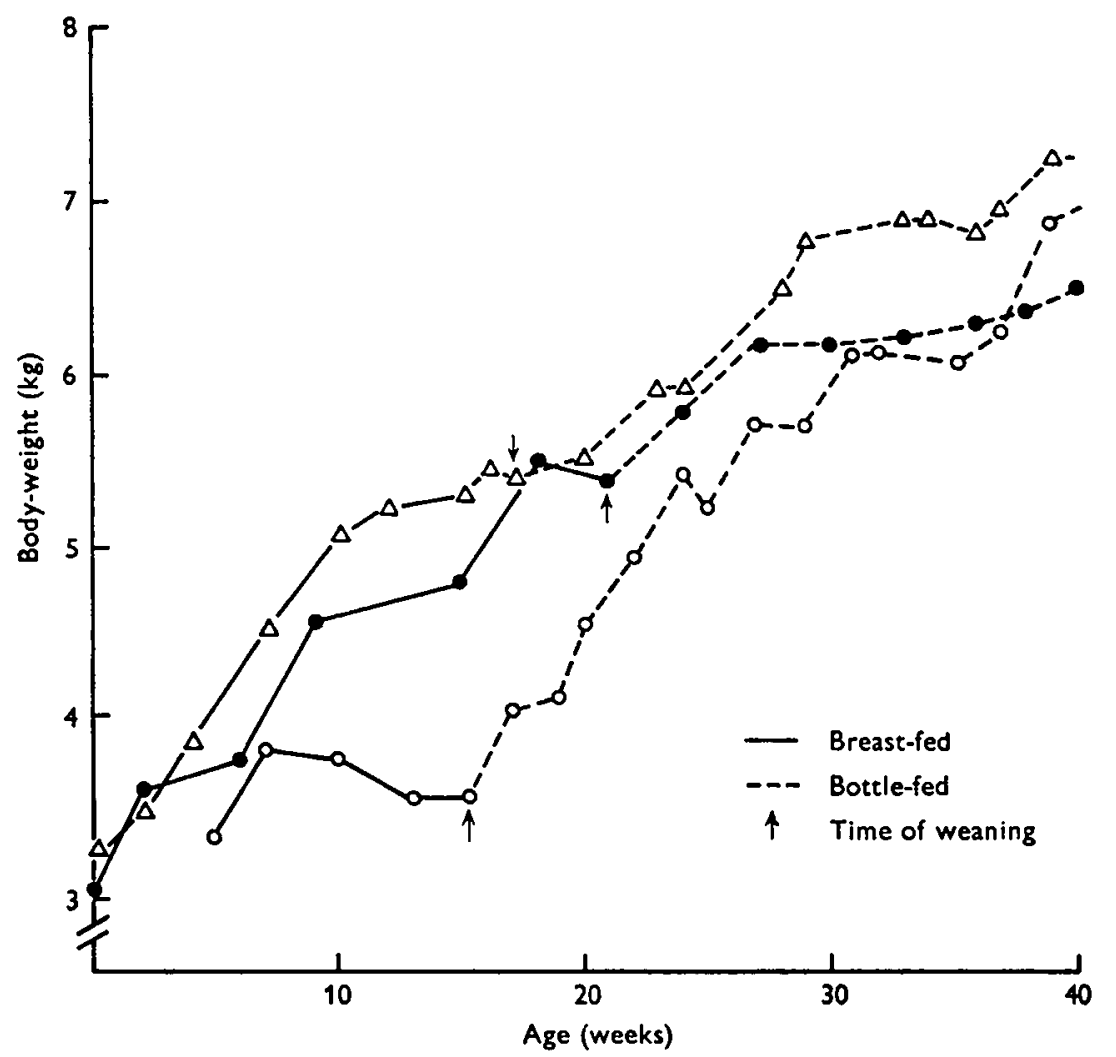

Fig. 3. Examples of growth curves of Malay infants showing the changes in growth rates which occurred following weaning.

\section{DISCUSSION}

Biologically, infant feeding involves only the mother and her infant. In paediatric and nutritional circles, it has been conventional to consider the mother-child unit in isolation. This is convenient nutritionally, but ignores the environment of the mother and child. The mother must consider the rest of her family as well as the newest infant. In many communities, both rural and urban, the earning capacity of the mother is essential to the well-being and even the survival of the family. There are, in Malaysia and probably other countries also, situations where the mother can either breast-feed her infant, or she can work, but she cannot do both. In rural areas of 
Vol. 26

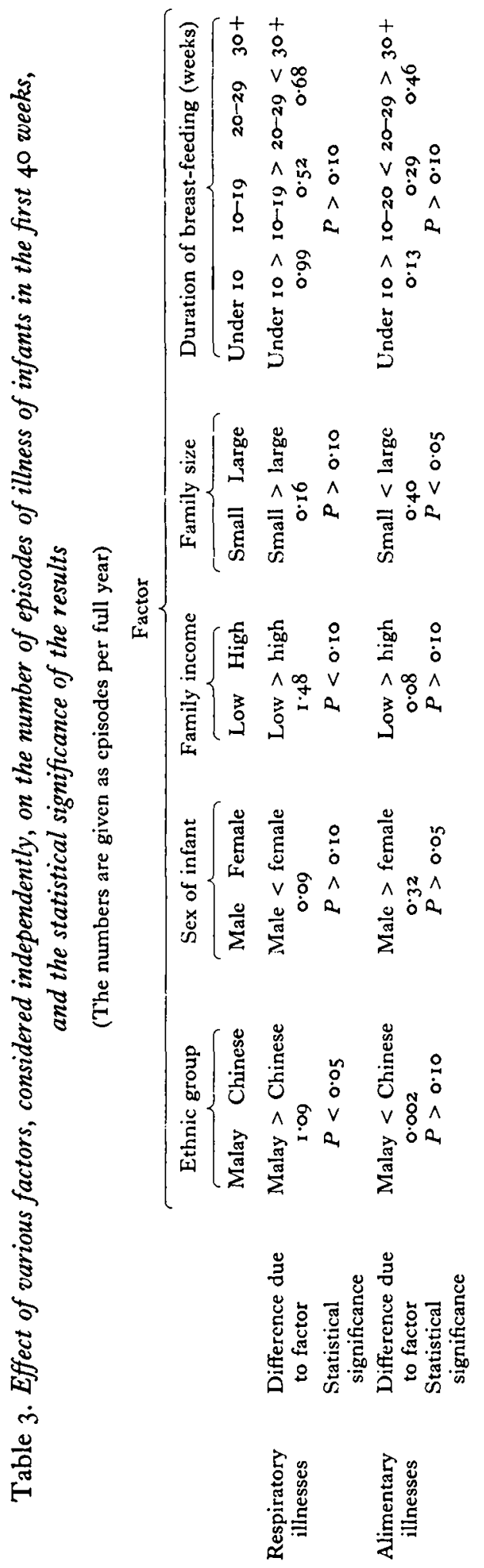


Malaysia, for example, rubber tapping demands constant movement which would be severely hampered by the presence of an infant; in urban areas, babies are not welcome in factories. The mothers must therefore often choose between breastfeeding and work and they must make their decision in the best interests of the whole family (McArthur, 1962). We must recognize the necessity for this decision, and help the mother to take the course which results in the greatest total benefit, or perhaps in the least total harm.

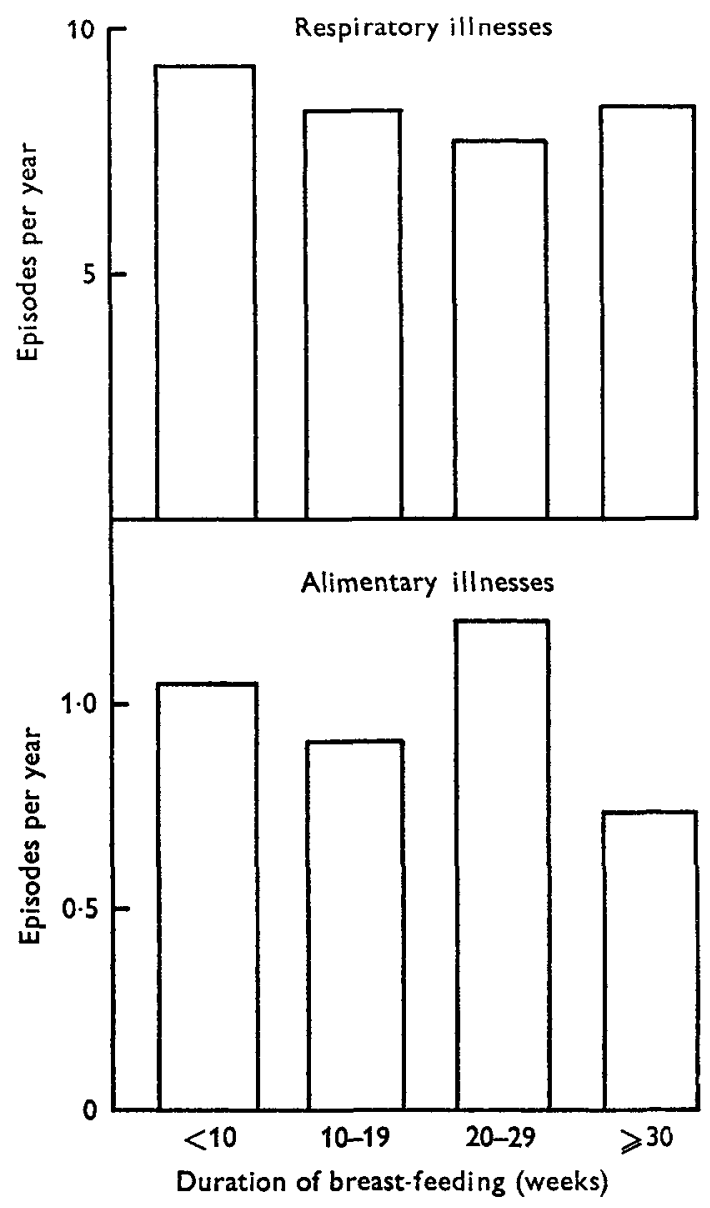

Fig. 4. Frequency of reported illnesses in Malay children during the first 40 weeks of life, computed as episodes per year, showing the effect of the duration of breast-feeding. Other children showed a similar pattern.

To make a rational decision, we should have some method of measuring the total welfare of the family. Such methods are very subjective and necessarily complex. I have therefore taken the other approach. The justification for breast-feeding is the increased welfare of the infant. Unless this increased welfare can be demonstrated, we cannot justify the advocation of breast-feeding if it may harm indirectly the rest of the family. The criteria for well-being of the infant have been taken as the weight gain and the rate of reported illnesses. 
The evidence from the $25^{\circ}$ children studied shows that breast-feeding may produce slightly greater weight gains up to the age of Io weeks, from Io-20 weeks there is no detectable difference, but after that, artificially fed infants gain considerably more weight than breast-fed infants. The method of analysis eliminates effects of the other factors on the effect of feeds, the differences are due to the type of feeds or to some other unknown and unconsidered factor. The demonstration of an increase in the rate of growth of some infants, when they were weaned, suggests that the type of feeding is the factor responsible.

The change in the growth pattern is likely to be due to underfeeding on breast milk, rather than overfeeding on artificial feeds. Underfeeding on breast milk is probably due to inadequate milk supply, which in turn may reflect inadequate maternal nutrition (Bailey, 1965 ).

The frequency of reported illnesses among these infants was affected by the race, family size and family income. Although not all differences reached the level of statistical significance $(P \leqslant 0.05)$, Malays had more illnesses than Chinese, and infants from low-income families had more illnesses than those from higher-income families. The sex of the infant and the size of the family had a variable effect. The effect of the type of feeding did not reach statistical significance, neither did it show any consistent trend. The epidemiological, as opposed to the statistical, significance of these findings, is difficult to assess. The illnesses were those reported to, or noted by, the clinic nurse, and therefore depend on the anxiety of the mother or the observation of the nurse. No direct assessment could be made of the hospital illnesses of these children because of difficulty in obtaining the hospital records. The record of illnesses is therefore subject to error and in the present study is probably not as reliable a guide as the growth achievement.

The group of infants whose growth and illnesses have been studied are obviously highly selected. They are infants from a particular environment who were brought to the $\mathrm{MCH}$ clinics frequently and whose mothers did not follow the MCH nurses' instructions about the introduction of solid foods. Can these findings be extrapolated?

There appears to be a continuous gradation of sophistication from the most primitive rural dwellers in undeveloped regions to the most sophisticated and educated persons who live mainly in the cities. For the infants of poor and ignorant families, a failure of the breast milk supply may be a virtual death sentence; in educated and wealthy families, the type of feeding is largely a matter of convenience for the mother rather than welfare of the infant. Somewhere between these extremes lies a zone where the family has some knowledge of infant hygiene, but suffers from economic deprivation. It is here that we must exercise judgement. The findings in this particular group suggest that breast-feeding confers little or no benefit on the infant, so the economic well-being of the whole family is more important. This conclusion can probably be applied to the local community, but cannot be extrapolated to other communities until their characteristics have been studied. If $\mathrm{MCH}$ staff and nutrition workers are to work rationally, they should know the situation in their own community and be prepared to advise the mother so as to maximize the total benefit to the family. 
I thank Dr L. S. Sodhy, Chief Medical Officer, Municipality of Kuala Lumpur, for allowing me to use the records of the MCH clinics; Dr J. Jeacock, formerly of the Department of Mathematics, University of Malaya, for assistance in the mathematical analysis; the Department of Medical Illustration, University of Malaya, and Mrs Ng Mo Tsing, for help with the illustrations and preparation of the manuscript.

\section{REFERENCES}

Bailey, K. V. (1965). F. trop. Pediat. 11, 35.

McArthur, A. M. (1962). Assignment Report WPR/449/62.

Oppé, T. E. \& Redstone, D. (I 968). Lancet i, ro45.

Scrimshaw, N. S., Taylor, C. E. \& Gordon, J. E. (1968). Monograph Ser. W.H.O. no. 57. 